\title{
ESTÁGIO CURRICULAR SUPERVISIONADO EM HISTÓRIA - PARFOR - UNOCHAPECÓ: LIMITES E POSSIBILIDADES
}

\author{
SUPERVISES ACADEMIC TRAINING IN HISTORY - PARFOR - UNOCHAPECÓ: \\ LIMITS AND POSSIBILITIES
}

Maria de Lurdes Pertile ${ }^{1}$

Sandra Agostini

\begin{abstract}
RESUMO: Este artigo originou-se de um estudo acerca do curso de Graduação licenciatura Plena em História - modalidade Plano Nacional de Formação de Professores - PARFOR, da Universidade Comunitária da Região de Chapecó UNOCHAPECÓ, e objetivou entender como os professores-estudantes ingressos no curso de História avaliam o Estágio Curricular Supervisionado enquanto elemento constitutivo de sua formação docente. Como fonte de informações para obtermos os dados de pesquisa, utilizamos o questionário de perguntas abertas. Os sujeitos de pesquisa foram 13 (treze) professores-estudantes atuantes em Escolas de Educação Básica - EEB da Rede Estadual e Municipal de Ensino da cidade de Chapecó-SC, e também, da Rede Estadual de Ensino da cidade de Gramado dos Loureiros-RS. Constatamos que o estágio é considerado de extrema importância, porém para o professor que já é licenciado, devemos fazer uso de outra modalidade de estágio, por exemplo, neste caso foi realizado o estágio na modalidade Curso de Extensão. Para a maioria (09) dos respondentes, foi boa a receptividade das escolas que possuem a tradição em recebê-los, no entanto, algumas (02) EEBs, necessitam assumir a sua corresponsabilidade entre os sistemas de ensino, conforme previsto na legislação vigente e, assim contribuir de maneira significativa no processo formativo do professor de segunda licenciatura.
\end{abstract}

Palavras-chave: Curso de História. PARFOR. Estágio Curricular Supervisionado. Professores-Estudantes.

\footnotetext{
1 Professora da Área de Ciências Humanas e Jurídicas e de Estágio em História, na modalidade PARFOR na Universidade Comunitária da Região de Chapecó - UNOCHAPECÓ/SC. Graduada em História, Especialista em História do Brasil e em Docência no Ensino Superior, Mestre em Educação pela PUC/RS

2 Mestre em Educação pela Universidade Federal de Santa Maria (UFSM), Professora Bolsista da CAPES, no Curso de História da Universidade Comunitária da Região de Chapecó UNOCHAPECÓ/SC, integrante do Plano de Formação de Professores da Educação Básica PARFOR, e Professora da Rede Estadual e da Rede Municipal de Ensino do Município de Chapecó/SC.
} 
ABSTRACT: This study gave rise from a study of the degree course in History PARFOR modality, of the Community College of the Chapecó Region - Unochapecó, and aimed to understand how the teachers students evaluate the Supervised academic training as a constituent element of their educational formation. As a source of information we use questionnaire with open questions. We note that the internship is considered of extremely importance, however for the teacher who is already licensed, we must make use of another type of stage. The majority (09) of respondents had a good acceptance of the school that has the custom to do this. However, some 2 (two) elementary schools, need to take their responsibility among the education schemes, as envisaged in the Current law and in this way to contribute significantly to the formation process of the teacher of second degree.

Keywords: History curse. PARFOR. Supervised Academic Training.

\section{Introdução}

Este estudo advém de pesquisa realizada no Curso de Graduação Licenciatura Plena em História ${ }^{3}$ - modalidade PARFOR $^{4}$, na Universidade Comunitária da Região de Chapecó - UNOCHAPECÓ, e objetivou entender como os professores-estudantes ingressos avaliam o Estágio Curricular Supervisionado enquanto elemento constitutivo de sua formação docente, buscando assim, sugestões que possibilitem a intervenção de inovações pedagógicas no ensino de História, visando contribuir de maneira significativa no processo formativo do professor de segunda licenciatura.

O Curso Graduação de Licenciatura Plena em História - modalidade PARFOR, foi instituído na UNOCHAPECÓ, no ano de 2010. O Curso funciona em Regime Especial, nos fins de semana (sextas e sábados) e nos meses de janeiro e julho.

3 UNIVERSIDADE COMUNITÁRIA DA REGIÃO DE CHAPECO. Curso de Graduação Licenciatura Plena em História: modalidade PARFOR. Aprovada pela Resolução n¹17/CONSUN/2009. Chapecó: Unochapecó, 2009.

4 O Plano Nacional de Formação de Professores (PARFOR), é um programa nacional implantado pela Coordenação de Aperfeiçoamento de Pessoal de Nível Superior (CAPES) em regime de colaboração com as secretarias de Estados, do Distrito Federal e dos Municípios e coma as Instituições de Ensino Superior (IES). O Objetivo do programa é garantir que os professores em exercício na rede pública de Educação Básica obtenham a formação exigida pela Lei de Diretrizes e Bases da Educação Nacional - LDB. Para se inscrever neste programa é necessário estar no exercício da docência na Educação Básica da rede pública, e atuar em disciplina para a qual está requerendo a matrícula, primeira ou segunda licenciatura. Fonte: freire.mec.gov.br. Acesso em: 02 fev. 2014. 
Atualmente, o curso conta com uma turma, cursando o $8^{\circ}$ período, num total de quinze acadêmicos regularmente matriculados na disciplina de Estágio de Docência em História III. Podendo esta modalidade ser realizada na forma de docência ou extensão, cujo público alvo pode ser, os estudantes ou os professores de História do Ensino Fundamental II.

Conforme a Proposta Curricular do Curso em vigência, objetivam-se as seguintes competências e habilidades do Egresso, as quais perpassam pelas diferentes etapas dos estágios de docência.

Competências: domínio das diferentes concepções teórico-metodológicas, em constante reelaboração, que fundamentam a construção das principais categorias da história (tempo, espaço, rupturas, permanências, identidade, memória, relações sociais, etc.) para investigação e análise das relações sócio históricas; Conhecimento das interpretações das principais escolas historiográficas, distinguindo as diferentes concepções teórico-metodológicas sobre História; Interpretação e intervenção qualificada nas diferentes fontes (escritas, orais, materiais, iconográficas, etc.); Avaliação crítica das concepções teórico-metodológicas do ensino de História e suas implicações na aprendizagem dos conteúdos históricos escolares.

Habilidades: analisar criticamente a realidade histórica do tempo presente e do espaço local vinculando-os com outras espacialidades (regional, nacional e mundial) e temporalidades; utilizar a pesquisa como princípio e prática permanente e necessária nos diferentes campos de atuação profissional de História; analisar, selecionar e problematizar as fontes documentais. Desenvolver a expressão oral e escrita na produção e divulgação do conhecimento histórico.

Para tanto, o Curso de História na modalidade PARFOR, desafia-se a promover o domínio do conhecimento histórico, pautando-se pela construção de saberes e competências, de forma autônoma e ética para a formação do profissional de História.

Em todos os processos de formação de professores, todas as experiências docentes vivenciadas, assim como o Estágio, assumem papel preponderante. De acordo com Pimenta e Lima: 
O estágio também pode servir de projetos interdisciplinares, ampliando a compreensão e o conhecimento da realidade profissional de ensinar. As experiências docentes dos alunos que atuam no magistério, como também daqueles que participam da formação continuada, devem ser valorizadas como referências importantes para serem discutidas $e$ refletidas nas aulas (PIMENTA; LIMA, 2004, p. 17).

Tanto do ponto de vista legal como da formação inicial e continuada de professores, faz-se necessária uma nova compreensão de estágio: de atividade prática e atividade teórico-prática sem, no entanto, dicotomizá-las. Sendo o Estágio a aproximação da realidade é também atividade teórica. Não somente prática educativa, pois não existe uma só. Existem várias, e não somente de sala de aula, portanto, deve ser propiciada a aproximação durante a graduação, na qual o acadêmico precisa dominar a estrutura conceitual da escola - campo de estágio - em cada turma diferente, de forma concreta.

A tônica principal do ensino de História não se resume em fixar determinados conteúdos. A própria Lei de Diretrizes e Bases - LDB n 9394/96, artigo 22, preza por: "[...] desenvolver o educando, assegurar-lhe formação comum indispensável para o exercício da cidadania e fornecer-lhe meios para progredir no trabalho e em estudos posteriores".

A História como disciplina escolar tem de oferecer meios e instrumentos para que o estudante possa pensar historicamente, para que se aproprie, utilizese e processe informações, para que se habilite a participar do processo histórico. Desenvolver as habilidades e competências para aprender e construir conhecimentos, são valores e princípios pedagógicos pelos quais os professores devem pautar-se.

\section{O perfil dos professores-estudantes que frequentam o Curso de História - PARFOR na UNOCHAPECó}

O Curso de Graduação Licenciatura Plena em História - modalidade PARFOR da UNOCHAPECÓ, do Regime Especial, é constituído de quinze professoresestudantes, sendo que o número da amostra de nossa pesquisa abarcou apenas 
treze participantes, devido à impossibilidade dos demais respondentes. O instrumento de pesquisa foi um questionário, contendo uma ficha de identificação e nove (09) questões.

A maioria (09) dos professores-estudantes são oriundos da região Oeste Catarinense residentes no município de Chapecó/SC, e apenas um reside no município de Gramado dos Loureiros no Estado do Rio Grande do Sul.

A faixa etária dos professores-estudantes que frequentam o Curso de História na UNOCHAPECÓ, varia entre vinte e seis (26) e cinquenta e sete (57) anos.

O tempo de atuação no magistério varia entre dois (02) a trinta e cinco anos (35), sendo que um dos respondentes já é aposentado, porém, ainda atua vinte (20) horas semanais na Rede Estadual de Ensino no município de Gramado dos Loureiros, Estado do Rio Grande do Sul.

O perfil profissional dos treze (13) professores-estudantes participantes da pesquisa revela:

- 01 professor tem Bacharel no Curso Superior de Tecnologia em Gestão e Recursos Humanos, cursando Pós-Graduação em nível de especialização;

- 02 professores tem curso de Graduação em Pedagogia e Pós-Graduação em nível de especialização;

- 01 professor tem curso de Tecnólogo em Administração Rural, curso de Graduação em Geografia e Pós-Graduação em nível de especialização;

- 01 professor tem curso de Bacharel em Teologia, curso de Graduação em Ciências da Religião e Pós-Graduação em nível de especialização;

- 01 professor tem curso de Graduação em Ciências da Religião e PósGraduação em nível de especialização;

- 01 professor tem curso de Graduação em Ciências da Religião;

- 01 professor tem curso de Graduação em Pedagogia;

- 01 professor tem curso de Graduação em Filosofia e Pós-Graduação em nível de especialização;

- 04 professores não possuem Curso de Ensino Superior. 
Conforme o exposto, constatamos que apenas quatro (04) professoresestudantes são efetivos e atuam na Rede Estadual de Ensino no município de Chapecó-SC. No entanto, os demais (09) exercem sua profissão na condição de Admitidos em Caráter Temporário - ACT. Sendo que cinco (05) atuam ministrando aulas referentes ao seu curso de primeira licenciatura, e quatro (04) já se encontram atuando na Rede Estadual e Municipal de Ensino na cidade de Chapecó-SC, como professores de História não habilitados.

\section{Procedimentos metodológicos: o princípio de pesquisa}

Para compreendermos os elementos apresentados pelos respondentes, referentes à avaliação e sugestões para a realização do Estágio Curricular Supervisionado, definimos como fonte e informações os sujeitos professoresestudantes e, como instrumentos para coletar as informações utilizamos o questionário de perguntas abertas (Apêndice 01) contendo uma ficha de identificação seguida de dez (10) questões abertas, sendo nove (09) questões referentes à avaliação geral do Estágio Curricular Supervisionado e uma questão (01) referente às sugestões acerca do tema

Conforme a definição de Richardson o questionário de perguntas abertas, "caracteriza-se por perguntas ou afirmações que levam o entrevistado a responder com frases ou orações. O pesquisador não está interessado em antecipar as respostas, deseja uma maior elaboração das opiniões do entrevistado (RICHARDSON, 1999, p. 192-193)".

Nesta pesquisa utilizou-se a integração entre análise qualitativa e quantitativa, pois ambas podem se complementar e assim possibilitar várias interpretações durante análise dos dados. De acordo com Lenoir: "colocam em evidência a complementaridade enriquecedora entre dois tipos de métodos, utilizados segundo combinações sequenciais ou em paralelo" (LENOIR, 2006, p.08).

Para desenvolvermos esse estudo, inicialmente, elaboramos o questionário de perguntas abertas, que foram entregues aos professores-estudantes do Curso 
de Graduação Licenciatura Plena em História - modalidade PARFOR, da UNOCHAPECÓ, que se encontravam cursando o $6^{\circ}$ período referente ao primeiro semestre do ano letivo de 2013.

Para a organização e a análise das informações obtidas no questionário, primeiramente, as respostas foram digitadas na íntegra, logo após fizemos a leitura das respostas, tantas vezes quanto necessário, para extrair a(s) ideia(s) central(is) expressas na resposta. Após a localização da(s) ideia(s) central(is) nas respostas, agrupamos aquelas que faziam referência a uma mesma indicação. Por fim, fizemos as constatações apresentando a quantidade de frequências nas respostas obtidas, e realizamos a análise das informações obtidas.

\section{Avaliação e sugestões para a realização do estágio curricular supervisionado no Curso de História - PARFOR da UNOCHAPECó: Constatações e resultados}

Após a leitura e análise dos questionários obtidos junto aos professoresestudantes inseridos no curso de licenciatura investigado, apresentamos as informações obtidas.

Percebemos que entre os motivos que despertaram o interesse para cursar História, apesar de quase todos (09) os respondentes já possuírem outro curso de Licenciatura Plena foram os seguintes: gostar de História, busca de conhecimento, gratuidade, ter mais possibilidades de trabalho e, ainda para a minoria (04) por ser o primeiro curso de graduação em Licenciatura Plena.

Em relação aos comentários feitos pelos respondentes a respeito do papel que representa o Estágio Curricular Supervisionado na formação de professores que já estão atuando nas Escolas de Educação Básica, evidenciamos que o Estágio Curricular para quase todos (09), foi considerado muito importante, pois foi considerado como uma nova aprendizagem, conforme nos relata o professor F: 
O Estágio Curricular Supervisionado tem como papel a intervenção prática na escola, é um momento que permite aos alunos a apropriação de instrumentos teóricos e metodologias para atuação no ambiente escolar. O estágio é uma parte significativa do curso de licenciatura. O papel do estágio é de grande importância, pois serve como uma pré-experiência do que irá ser vivido depois da graduação mesmo quando o aluno já tenha passado por outros estágios, ou esteja atuando na educação básica. A cada estágio vive-se uma nova experiência (Professor F).

No entanto, para três (03) respondentes o Estágio Curricular Supervisionado foi considerado desnecessário. Os depoimentos abaixo comprovam essas percepções:

Um papel de repetição (...) de reinvenção da roda (Professor B).

Apenas um requisito/normas do chamado sistema, pois não vejo nenhuma necessidade afinal essa é cotidiana (Professor $A$ ).

Penso que o estágio pra quem já está em sala de aula é uma perda de tempo, avalio não ser necessário (Professor $L$ ).

No que se refere às informações obtidas junto aos professores-estudantes, acerca de com quais saberes eles veem construindo sua identidade docente evidenciamos que no geral estão pautados na busca de novos saberes e conhecimentos, a partir de leituras realizadas, das próprias experiências e, também, centra-se na fuga dos percursos tradicionais de ensino.

Em relação à análise referente à forma com os respondentes foram recebidos, e como se relacionaram com as escolas para a realização do Estágio Curricular Supervisionado, percebemos que foi unânime a boa receptividade dos professores-estudantes com as escolas. Porém, no que se refere à relação com a escola, apenas três (03) respondentes sentiram falta de colaboração por parte da Equipe Diretiva, pois esta "deixou a desejar", no sentido que não auxiliou os estagiários no decorrer da realização do Estágio Curricular Supervisionado. Sendo que os mesmos não foram comunicados quando havia mudanças no horário escolar e consequentemente alterações no turno de aulas do professor regente de turma, levando-os a se deslocarem até à escola em vão, e somente 
ao chegarem lá para ministrar as aulas é que recebiam o aviso a respeito das modificações realizadas.

Então, perante esse fato somos levadas a questionar, o porquê desse descaso da escola com o futuro profissional que nela já atua ou irá atuar? Segundo a Resolução do Conselho Nacional de Educação - CNE/CP no 1 de fevereiro de 2002 no Art. 13, parágrafo 3 define:

O estágio obrigatório a ser realizado em escola de educação básica, e respeitando o regime de colaboração entre os sistemas de ensino, deve ter início desde o primeiro ano a ser avaliado conjuntamente pela escola formadora e a escola campo de estágio (RESOLUÇÃO, CNE/CP01, 2002, p.06).

Nesse sentido, a escola parece não entender a sua corresponsabilidade no processo de formação de professores, negligenciando informações essenciais aos estagiários, isentando-se de suas funções de interação com a universidade, conforme previsto na legislação vigente que está norteando o desenvolvimento do Estágio Curricular Supervisionado, prejudicando dessa maneira o processo de formação inicial de professores.

Em relação à análise referente aos desafios e as dificuldades que os professores-estudantes enfrentaram para a realização do Estágio Curricular Supervisionado, evidenciamos no quesito alusivo as dificuldades que foi unânime conciliar o vínculo profissional com as aulas de estágio, os recursos tecnológicos precários para o uso. E, no quesito referente aos desafios enfrentados no decorrer do Estágio, constatamos que no geral foram o medo, o planejamento das aulas, a indisciplina e o grande número e alunos em sala de aula, transmitir o conteúdo com clareza e persuasão, e para um respondente foi tentar fazer a diferença na modalidade Curso de Extensão.

No que se referem às colocações feitas pelos professores-estudantes a respeito de quais foram às inovações em termos de prática em sala de aula que eles introduziram durante a realização do seu Estágio Curricular Supervisionado, percebemos que no geral não teve práticas inovadoras, todos salvo exceção que realizou na modalidade Curso de Extensão, fizeram uso de mapas, painéis, pesquisas, aulas expositivas dialogadas, vídeo, Data show, ou seja, conseguiram 
ministrar suas aulas de acordo com as condições oferecidas em cada instituição de ensino, conforme nos relata o professor B:

\begin{abstract}
Faz-me rir. Inovações num sistema totalmente arcaico, onde os educandos são privados de acesso a tecnologias, a mídia tão difundidas politicamente, que estão somente na fala, mas na realidade não são iguais para todas as unidades de ensino (...) Levamos a tecnologia do notebook a eles. Também conseguimos um Data show para assistir um filme. Ao meu modo de ver não foram inovações, mas oportunidade de levar algo diferenciado ao educando a mercê (Professor B).
\end{abstract}

No que diz respeito à maneira como os professores-estudantes foram acompanhados pelos professores regentes de turma para a realização do Estágio Curricular Supervisionado, constatamos que a maioria (11) dos respondentes recebeu todo o apoio necessário para a realização de um bom estágio. No entanto, tivemos dois respondentes para os quais o professor regente deixou de exercer na plenitude sua função, pois um respondente não recebeu nenhum tipo de acompanhamento. $\mathrm{E}$, o outro, o professor regente auxiliou na organização do estágio, porém não se fez presente no decorrer das aulas.

Em relação à opinião dos professores-estudantes, no que se refere ao relacionamento com o professor regente de turma para a realização do Estágio Curricular Supervisionado, podemos destacar alguns aspectos que para a maioria (11) foram considerados positivos, tais como: diálogo, acolhedor, atenção, companheirismo, compreensão, ética, seriedade, comprometimento, prestativo e profissional.

Com relação aos aspectos considerados negativos no relacionamento com o professor regente de turma para dois respondentes foi à falta de acompanhamento no decorrer das aulas de estágio.

Conforme os depoimentos dos professores-estudantes, no que se refere às sugestões a serem assumidas e implementadas para o bom desenvolvimento do Estágio Curricular Supervisionado, tanto pelas Instituições de Ensino Superior (IES), quanto pelas EEBs, podemos sintetizar como: a primeira deveria mudar os métodos de ensino para os professores que já são licenciados, deveria oferecer Curso de Extensão com direito a certificado para o educador e educando, propor 
produção de artigo e desenvolver mais atividades prática. A segunda deveria instruir-se e preparar-se melhor para receber o futuro profissional, assim como receber e manter um bom relacionamento com os estagiários estando mais aberto ao diálogo.

Em relação aos comentários feitos pelos professores-estudantes a respeito da avaliação do Estágio Curricular Supervisionado que eles realizaram evidenciamos que para a maioria (11) dos respondentes o Estágio Curricular Supervisionado foi considerado como um ótimo momento de aprendizagem proporcionando novas vivências e experiências na formação inicial de professores. No entanto, para dois respondentes o Estágio Curricular Supervisionado, foi considerado uma fase de experiências negativas em função, principalmente do número de alunos em sala de aula e pela indisciplina dos mesmos e também pelo escasso tempo designado para a realização do Estágio Curricular Supervisionado.

Na nossa concepção, o Estágio Curricular Supervisionado é considerado como espaços de formação, aprendizagem, produção de conhecimentos, pesquisa e, sobretudo, o encontro entre a teoria e a prática.

Percebemos, com base em nossa pesquisa que o Estágio Curricular Supervisionado se configura como espaço de formação que proporciona o contato com o seu campo de trabalho, e neste caso, mesmo aos professoresestudantes, que já vivenciaram outros estágios, e também já se encontravam atuando nas EEBs, na condição de professor efetivo ou ACT não habilitado conviver com uma nova experiência de ensino e aprendizagem no âmbito escolar.

\section{Considerações finais}

Após ter compartilhado com as vivências e experiências de ensino abordadas pelos professores-estudantes, acreditamos que este trabalho poderá contribuir para que nós professores também de IES, possamos a partir das avaliações positivas e negativas acerca da organização e desenvolvimento do 
Estágio Curricular Supervisionado, repensar possibilidades a serem implementadas no processo formativo de professores, visando suprir as lacunas mencionadas na formação do professor de segunda licenciatura.

Percebemos, com base em nossa pesquisa que o Estágio Curricular Supervisionado se configura como um espaço de ensino e aprendizagem o qual tem a função de colocar o professor em contato com seu campo de trabalho, proporcionando uma experiência única, de como exercer sua profissão em situações reais de ensino. $E$, neste caso, mesmo sendo professores de segunda licenciatura, e também, já tendo realizado outros estágios, constatamos que a experiência resultou em um novo aprendizado, e por isso, foi considerado pela maioria (09) dos respondentes como de extrema importância.

Contudo, nossa investigação apresentou alguns (03) casos em que o Estágio Curricular Supervisionado foi considerado desnecessário pelo fato de já serem professores atuantes nas EEBs. Em seus registros não foi possível perceber aprendizagem específica de vida com a realização de seus estágios.

Constatamos que os professores-estudantes, veem construindo sua identidade docente a partir da incessante e incansável busca pelo conhecimento, assim como, pelas vivências e experiências no decorrer de seu cotidiano no exercício da docência nas EEBs.

Pudemos perceber que, no geral os professores-estudantes foram bem recebidos pelas escolas que possuem uma tradição em recebê-los, ou seja, que fazem parte do Convênio intitulado: "Programa Universidade-Escola para Formação Docente ${ }^{5 \prime}$. Porém, no que se refere à relação com a escola, nossa investigação mostrou que a Equipe Diretiva de algumas (02) instituições de ensino precisam entender e aceitar a sua corresponsabilidade no processo de formação de professores.

No que tange o relacionamento entre os professores-estudantes e o professor regente de turma, podemos afirmar que há um bom empenho por

\footnotetext{
${ }^{5}$ O Programa Universidade-Escola para Formação Docente propõe as bases de uma parceria entre a UNOCHAPECÓ e os estabelecimentos de ensino de diferentes níveis e redes, tendo como ponto de partida uma nova metodologia para a realização dos estágios nos cursos de licenciatura da UNOCHAPECÓ.
} 
parte destes docentes em auxiliá-los em todas as dificuldades encontradas em sala de aula.

Com base na análise referente aos problemas enfrentados pelos professores-estudantes, no decorrer da realização do Estágio Curricular Supervisionado, podemos afirmar que estas dificuldades se centraram em conseguir conciliar o vínculo profissional com os horários das aulas de estágio, assim como, a precariedade de recursos tecnológicos, e também a ausência dos mesmos para uso nas escolas.

Mediante as sugestões feitas pelos professores-estudantes, tanto para a IES, quanto pelas EEBs, visando melhorar o processo de organização e desenvolvimento do Estágio Curricular Supervisionado, percebemos que a IES, deve oferecer outra modalidade de Estágio Curricular Supervisionado, como neste caso, o curso já vem ofertando a modalidade Curso de Extensão para o professor de segunda licenciatura.

Já as EEBs, em especial, a Equipe Diretiva, deverá receber um curso de formação, para receber os estagiários nas escolas, e assim, cumprir com o previsto na Resolução CNE/CP 1/2002, em seu artigo 13, parágrafo 3, quando faz referência à "colaboração entre os sistemas de ensino".

Numa perspectiva de investigação, onde o educador tem em mãos a responsabilidade de utilizar o método de pesquisa ao invés do método de ensino, mesmo sendo eles interdependentes.

Sem reducionismos culturais e contribuições isoladas e passadistas, cotidianamente transformamos e reelaboramos nossas práticas pedagógicas. 0 respeito às diferenças é o caminho na construção de uma sociedade mais democrática, e isto a história nos ensina.

Assim, buscou-se uma reflexão maior sobre as diferentes possibilidades de ação pedagógica e um estímulo para investigação técnica-científica no campo histórico.

Por fim, a partir deste estudo, ofertamos outra modalidade de estágio no curso em estudo, ou seja, o Curso de Extensão, assim como, continuaremos juntos a buscar caminhos que possam conduzir o Estágio Curricular Supervisionado, sobretudo em História a suprir as lacunas mencionadas e 
contribuir de maneira significativa no processo formativo do professor, em especial, o de segunda licenciatura.

\section{Referências}

BRASIL, Ministério da Educação, Conselho Nacional de Educação. Resolução CNE/CP 1 de 18 de fevereiro de 2002 - Institui Diretrizes Curriculares Nacionais para a Formação de Professores da Educação Básica, em nível superior, cursos de Licenciatura, de graduação plena. Brasília: Diário Oficial da União, 09 Abr. 2002 1, p.31. Disponível em:

<http:/portal.mec.gov.br/cne/arquivos/pdf/cp22002.pdf> Acesso em: 22 fev. 2014.

BRASIL, Ministério da Educação. Lei de Diretrizes e Bases da Educação Nacional no 9.394/96 - Estabelece as Diretrizes e Bases da Educação Nacional.

Brasília/BR: MEC, 1996. Disponível em: <htt://www.planalto.gov.Br>. Acesso em: 16 jan. 2015.

GUAZZELLI, C. A. B.; PETERSEN, S. R. F.; SCHMIDT, B. B.; XAVIER, R. C. L. Questões de Teoria e Metodologia da história. Porto Alegre: Ed.

Universidade/UFRGS, 2000.

LENOIR, Yves. Pesquisar e formar: repensar o lugar e a função da prática de ensino. Educação e Sociedade. Campinas, v.27, n.97, p.1299-1325, 2006.

Disponível em:

<http:/WWW.scielo.br/scielo.php?script=sciartex\&pid=S0101733302006000400 011\&Ing=PT\&nrm=isso $>$. Acesso em: 20 Fev. 2014.

KARNAL, L. (Org.). História na sala de aula: conceitos, práticas e propostas. $2^{a}$ ed. São Paulo: Contexto, 2004.

PIMENTA, S. G.; LIMA, M. S. L. Estágio e docência. São Paulo: Cortez, 2004.

RICHARDSON, R. J. Pesquisa Social: métodos e técnicas. 3 ed. São Paulo: Atlas, 1999.

THOMPSON, E. P. O Tempo Ausente: experiência. In: . A Miséria da Teoria. Rio de Janeiro: Zahar, 1981, p. 180 - 201.

UNIVERSidAde COMUNITÁRIA DA REGIÃo DE CHAPECO. Projeto Político Pedagógico do Curso de Licenciatura de Graduação Plena em História. Aprovado pela Resolução n¹32/CONSUN/2006 em 20 de novembro de 2006. Chapecó: Unochapecó, 2006. 
UNIVERSIDADE COMUNITÁRIA DA REGIÃO DE CHAPECO. Curso de Graduação Licenciatura Plena em História: modalidade PARFOR. Aprovado pela Resolução n¹17/CONSUN/2009 em 13 de outubro de 2009. Chapecó: Unochapecó, 2009.

UNIVERSIDADE COMUNITÁRIA DA REGIÃO DE CHAPECO. Credenciada pelo Decreto Estadual no. 5.571, de 27 de agosto de 2002. Recredenciada pelo Decreto Estadual no. 659, de 25 de setembro de 2007, publicada no Diário Oficial de Santa Catarina. Disponível em: <http://www.unochapeco.edu.br/info/aunochapeco>. Acesso em: 05 de set. de 2015. 


\section{APÊNDICE 01}

UNIVERSIDADE COMUNITÁRIA DA REGIÃO DE CHAPECÓ - UNOCHAPECÓ

ÁREA DE CIÊNCIAS HUMANAS E JURÍDICAS

CURSO DE LICENCIATURA PLENA EM HISTÓRIA - MODALIDADE PARFOR

\section{QUESTIONÁRIO PARA ALUNOS ESTAGIÁRIOS DO CURSO DE LICENCIATURA PLENA EM HISTÓRIA- MODALIDADE PARFOR - UNOCHAPECÓ}

Ficha de Identificação, Atuação Profissional e Formação Acadêmica:

\begin{tabular}{|c|c|}
\hline & Identificação \\
\hline Professor(a) & $\begin{array}{l}\text { Nome: } \\
\text { Idade: } \\
\text { Fones de contato: } \\
\text { Res: ( ) } \\
\text { E-mails: }\end{array}$ \\
\hline Escola & $\begin{array}{l}\text { Atuação Profissional } \\
\text { Nome: } \\
\text { Endereço da Escola: } \\
\text { Regime de trabalho/horas: } \\
\text { ( ) Nomeação/_horas } \\
\text { ( ) Contrato/_horas } \\
\text { ( ) Convocação__ horas } \\
\text { Total de horas : } \\
\text { Disciplina(s) que leciona/lecionou: } \\
\text { Ano de ingresso no Magistério Estadual: } \\
\text { Ano de ingresso no Magistério Municipal: } \\
\text { Ano de ingresso no Magistério Privado: } \\
\text { Tempo de atuação no Magistério: } \\
\text { Tempo de atuação como Coordenação Pedagógica (Supervisão): }\end{array}$ \\
\hline $\begin{array}{l}\text { Curso de } \\
\text { Graduação }\end{array}$ & $\begin{array}{l}\text { Formação Acadêmica } \\
\text { Graduação/Licenciatura em: } \\
\text { Instituição: } \\
\text { Cidade/UF: } \\
\text { Ano de Conclusão: } \\
\text { Outra graduação em: } \\
\text { Instituição: } \\
\text { Curso de Pós-Graduação } \\
\text { Especialização em: } \\
\text { Instituição: } \\
\text { Cidade/UF: } \\
\text { Ano de Conclusão: }\end{array}$ \\
\hline
\end{tabular}




\section{Curso na área de Formação \\ de \\ Professores}

\section{Formação complementar}

Participa de cursos de Formação em Gestão Escolar ( ) sim ( ) não

E caso afirmativo, especifique o curso/instituição/ano

\section{Avaliação geral e sugestões para a realização do Estágio Curricular Supervisionado}

1. O que o motivou a ingressar no Curso de História, sendo que você já é graduado em outro curso de Licenciatura Plena?

2. Que papel você atribui ao Estágio Curricular Supervisionado, na formação de professores que já são graduados e estão atuando nas Escolas de Educação Básica?

3. Com que saberes e conhecimentos você vem construindo sua identidade docente?

4. De que forma você foi recebido e como foi a sua relação com a escola?

5. Que desafios, dilemas ou dificuldades você enfrentou durante a realização de seu Estágio Curricular Supervisionado neste semestre?

6. Que inovações, em termos de prática em sala de aula, você introduziu durante a realização do seu Estágio Curricular Supervisionado neste semestre? Identifique tais inovações e comente-as.

7. Que tipo de acompanhamento você recebeu do seu professor(a) regente da turma de estágio?

8. Comente, como foi seu relacionamento com o(a) professor(a) regente da turma, apontando aspectos que você considera positivos e negativos. 
9. Após ter vivenciado novamente a experiência do Estágio Curricular Supervisionado, que sugestões você deixaria para serem assumidas e implementadas:

a) pelas universidades;

b) pelas Escolas de Educação Básica.

10) Como você avalia o seu próprio desempenho durante o Estágio Curricular Supervisionado? 